\title{
DAMAGE HAZARD MODEL FOR CHOSEN ELEMENT OF THE AIRCRAFT STRUCTURE TAKING INTO ACCOUNT FATIGUE CRACK DEVELOPMENT STAGES
}

\author{
MODEL RYZYKA USZKODZENIA WYBRANEGO \\ ELEMENTU KONSTRUKCJI STATKU \\ POWIETRZNEGO Z UWZGLĘDNIENIEM ETAPÓW \\ ROZWOJU PĘKNIĘCIA ZMĘCZENIOWEGO
}

\author{
Henryk Tomaszek ${ }^{1}$, Józef Żurek², Michał Jasztal ${ }^{3}$ \\ $(1,2)$ Air Force Institute of Technology, 01-494 Warsaw ul. Ksiecia Bolesława 6 \\ (3) Military University of Technology, Faculty of Mechatronics, \\ 00-908 Warsaw ul. Gen. Sylwestra Kaliskiego 2 \\ e-mails: (2) jozef.zurek@itwl.pl, (3) Michal.Jasztal@wat.edu.pl
}

\begin{abstract}
The subject of the present paper is the modeling of aircraft structure fatigue processes which endanger flight safety. It is assumed that the simple course of the process of aircraft structure elements fatigue encompasses the following stages: initiation of cracks, crack development to the limit value, destruction of the element of structure. These stages can be taken as random incidents or random processes. The paper provides a description of the two initial stages as random processes. The relations obtained allow to define the reliability of the structure element and to evaluate the damage hazard in given time period.
\end{abstract}

Key words: fatigue crack, stress intensity factor, damage hazard, fatigue life.

Streszczenie. Referat dotyczy modelowania procesów zmęczenia konstrukcji statku powietrznego, które zagrażają bezpieczeństwu lotów. Przyjmuje się, że prosty przebieg procesu zmęczenia elementów konstrukcji statku powietrznego obejmuje etapy: inicjacji pęknięć, wzrostu pęknięcia do wartości granicznej, zniszczenia elementu konstrukcji. Etapy te można traktować jako zdarzenia losowe lub procesy losowe. Referat obejmuje opis pierwszych dwóch etapów jako procesów losowych. Otrzymane zależności pozwalają określić niezawodność elementu konstrukcji i oszacować ryzyko uszkodzenia w przyjętym przedziale czasu.

Słowa kluczowe: pękanie zmęczeniowe, współczynnik intensywności naprężeń, ryzyko uszkodzenia, trwałość zmęczeniowa. 


\section{DAMAGE HAZARD MODEL FOR CHOSEN ELEMENT OF THE AIRCRAFT STRUCTURE TAKING INTO ACCOUNT FATIGUE CRACK DEVELOPMENT STAGES}

\section{Introduction}

It is assumed that process of catastrophic failures development from the fatigue point of view is divided into stages. Simple course of failure process covers three basic stages:

- crack initiation

- crack development,

- structure element destruction.

The process of catastrophic damage hazard development (in special case) begins with a crack initiation which leads to the development of a crack of adequate length in the case of which relationships describing the crack development, e.g. the Paris formula, apply.

The period during which the process of crack initiation takes place is a stage preceding the fundamental process of crack length development to the critical value at which the element destruction follows. The stage of the crack initiation can be treated as the first stage of element destruction which is followed by the second stage, including the crack development to the critical value. This way, one can assume that parallel reliability structure of element destruction occurs, including the crack initiation, its development and the stage of unexpected structure destruction.

\section{Determination of crack initiation probability on the basis of reliability terms}

In the probabilistic description of the element damage, the basic factor to be taken into account is the intensity of damages. In the description of element crack initiation probability, this term will be used to exchanging the damage intensity for the term of initiation intensity. The intensity of the crack initiation will be described by the formula:

$\chi(t)=\lim _{\Delta t \rightarrow 0^{+}} \frac{P(t<T<t+\Delta t / T>t)}{\Delta t}$

where: 
$T$ - random variable describing the time period in which the crack initiation took place,

$t$ - operation time of the examined structure element,

$\mathrm{P}(. .$.$) - probability of conditional event.$

For any two $\mathrm{A}$ and $\mathrm{B}$ conditional events the following relation occurs :

$P(A / B)=\frac{P(A \cap B)}{P(B)}$

Event $\{t<T<t+\Delta t\} \cap\{t<T\}$ coincides with the event $\{t<T<t+\Delta t\}$. Making use of the above-mentioned relations, formula (1) can be presented as follows:

$\chi(t)=\lim _{\Delta t \rightarrow 0^{+}} \frac{P(t<T<t+\Delta t)}{\Delta t P(T>t)}$

From where

$\chi(t)=\frac{f(t)}{R_{1}(t)}=\frac{-R_{1}^{\prime}(t)}{R_{1}(t)}$

where:

$f(t)$ - crack initiation time density function,

$R_{1}(t)$ - probability that in the time period $(0, t)$ there will not be any crack initiation.

Formula (3) can be presented as the following differential equation: $R_{1}^{\prime}(t)+\chi(t) R_{1}(t)=0$

Equation (4) for the initial condition $R(t=0)=1$ has the following

solution: $R_{1}(t)=e^{-\int_{0}^{t} \chi(t) d t}$

Formula (5) describes the probability of the fact that in the period $(0, t)$ there will not be any initiation of crack. Hence the probability of crack initiation in the time period $(0, t)$ will be described by the formula:

$Q_{1}(t)=1-R_{1}(t)$

Where $\chi(t)=\chi=$ const , the relations of (5) and (6) take form:

$R_{1}(t)=e^{-\chi \cdot t}$

$Q_{1}(t)=1-e^{-\chi \cdot t}$

Estimation of the crack intensity $\chi$ can be performed by using the relation developed from the application of moments principle : 


$$
\chi=\frac{w}{\sum_{k=1}^{w} t_{k}}
$$

where: $w$ - number of elements observed during aircraft operation, $t_{k}$ - it is the time to the moment of the crack initiation in $k$ system calculated from the beginning of operation.

\section{Determination of crack initiation probability as random process}

It is assumed that the crack initiation in the element takes place as a result of accumulation of internal element structure degradation as an effect of variable load activity. As a result of variable load activity, the accumulation of fatigue symptoms occurs in different places of the element e.g. on the different kind of "obstacles".

It is assumed that among the places of the activity results accumulation, one of them is leading and the initiation takes place in it, as a result of fatigue accumulation effect; for example, on this given "obstacle", dislocation concentration, among others, takes place in its vicinity.

Let $\Psi$ be a parameter that is used for the measurement of the accumulated destruction symptoms of the structure element around the obstacle. Thus, it can be accepted that the prognostic parameter estimating the chance of crack development (its initiation) is $\Psi$ parameter. We perform the digitization of prognostic $\Psi$ parameter in the following way: $E_{0}, E_{1}, E_{2}, \ldots, E_{k}, \ldots$ these points are called the states of fatigue development effect before the crack initiation as a result of load acting. The accumulated symptoms of fatigue around the obstacle support the crack initiation.

It is assumed that from any state there is a specific probability of the crack development (crack initiation). Together with the development of the state $E_{i}(i=0,1,2, \ldots)$, the increase in the probability of the crack initiation takes place.

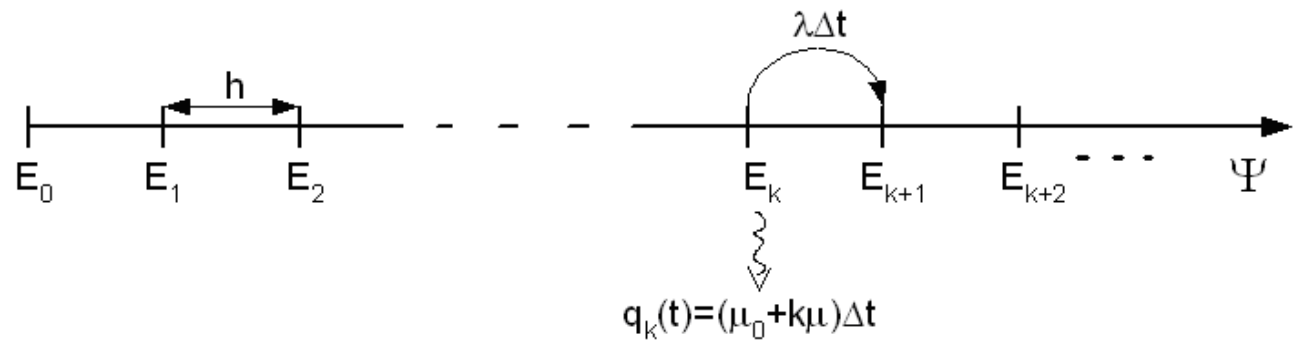

Fig.1. Diagnostic parameter digitization diagram 
Figure 1 presents the increasing of fatigue symptoms around the obstacle as a result of loading which is connected to attaining higher and higher state. The factor to force the state change is the probability of appearance of loading cycle $\lambda \Delta t$ where $\lambda$ is the intensity the appearance of loading element cycle. There is a probability of crack initiation in any state.

$q_{k}(t)=\left(\mu_{0}+k \mu\right) \Delta t$

where:

$\mu_{0}$ - intensity of crack initiation at the initial moment,

$k \mu$ - intensity of crack initiation dependent on the accumulated fatigue results state,

$h$ - average value of diagnostic parameter increase in $\Delta t$ period, $\lambda \Delta t$ - probability of an appearance of element loading cycle in $\Delta t$ period.

Let $P_{k}(t)$ denote the probability that at the moment $t$, the value of diagnostic parameter reached the state $E_{k}$ (where $k=0,1,2, \ldots$ ). For these assumptions one can create the following system of equations (of infinite quantity of equations) [1]:

$P_{0}(t+\Delta t)=P_{0}(t)\left[1-\left(\mu_{0}+\lambda\right) \Delta t\right]+0(\Delta t)$

$M$ for $k=1,2, \ldots$

$P_{k}(t+\Delta t)=P_{k}(t)\left[1-\left(\mu_{0}+k \mu+\lambda\right) \Delta t\right]+P_{k-1}(t) \lambda \Delta t+0(\Delta t)$

After converting and dividing the both sides of $k$ equation by $\Delta t$ while coming to the limit from $\Delta t \rightarrow 0$ the following equation system is obtained: $P_{0}^{\prime}(t)=-\left(\mu_{0}+\lambda\right) P_{0}(t)$

$M$

$$
\text { for } k=1,2 \ldots \ldots \ldots
$$

$P_{k}^{\prime}(t)=-\left(\mu_{0}+\lambda+k \mu\right) P_{k}(t)+\lambda P_{k}(t)$

The initial condition for both of these equations can be written as follows:

$P_{i}(0)=\left\{\begin{array}{l}1 \text { dla } i=0 \\ 0 \text { dla } i \neq 0\end{array}\right.$

Solution for $k=0$ :

$P_{0}(t)=-C_{0} e^{-\left(\mu_{0}+\lambda\right) t}$

Solution for any $k$ :

$P_{k}(t)=\frac{1}{k !}\left(\frac{\lambda}{\mu}-\frac{\lambda}{\mu} e^{-\mu t}\right)^{k} e^{-\left(\mu_{0}+\lambda\right) t}$ 
for $k=1,2,3 \ldots$

Making use of the relationships of (14) and (15), the element reliability can be determined:

$$
\begin{aligned}
& R(t)=\sum_{k=0}^{\infty} P_{k}(t) \\
& R(t)=\sum_{k=0}^{\infty} \frac{1}{k !}\left(\frac{\lambda}{\mu}-\frac{\lambda}{\mu} e^{-\mu t}\right)^{k} e^{-\left(\mu_{0}+\lambda\right) t}
\end{aligned}
$$

It should be noticed that the following equation occurs:

$$
\sum_{k=0}^{\infty} \frac{1}{k !}\left(\frac{\lambda}{\mu}-\frac{\lambda}{\mu} e^{-\mu t}\right)^{k}=e^{\frac{\lambda}{\mu}-\frac{\lambda}{\mu} e^{-\mu t}}
$$

Hence:

$$
R(t)=e^{\frac{\lambda}{\mu}\left(1-e^{-\mu t}\right)-\left(\mu_{0}+\lambda\right) t}
$$

The probability that to the $t$ moment a crack initiation will not occur can be described by the relationship:

$R_{1}(t)=\sum_{k=0}^{\infty} P_{k}(t)$

The probability that to the $t$ moment a crack initiation will occur can be described by the relationship:

$Q_{1}(t)=P\{T \leq t\}=1-R_{1}(t)=F(t)$

After addition the following solution is obtained:

$Q(t)=F(t)=1-e^{\frac{\lambda}{\mu}-\left(\lambda+\mu_{0}\right) t-\frac{\lambda}{\mu} e^{-\mu t}}$

Relationship (21) describes the probability of crack initiation in $(0, t)$ period of time.

\section{Relationship for determination of the crack increase after initiation}

In the work [4], the function of the crack length density was described as $m \neq 2$.

$u(l, t)=\frac{1}{\sqrt{2 \pi A(t)}} e^{-\frac{(l-B(t))^{2}}{2 A(t)}}$

where:

$l$ - crack length 
$t$ - aircraft flying hours

$B(t) \quad$ - crack length expected value for $m \neq 2$ described by the formula:

$B(t)=\left[l_{o}^{\frac{2-m}{2}}+\frac{2-m}{2} \lambda C M_{k}^{m} \pi^{\frac{m}{2}} E\left[\left(\sigma^{\max }\right)^{m}\right] t\right]^{\frac{2}{2-m}}-l_{o}$

$A(t)$ - variance of the crack length for $m \neq 2$ described by the formula:

$A(t)=\frac{2}{2+m} C M_{k}^{m} \pi^{\frac{m}{2}} \frac{E\left[\left(\sigma^{\max }\right)^{2 m}\right]}{E\left[\left(\sigma^{\max }\right)^{m}\right]}$.

$$
\cdot\left[\left(l_{o}^{\frac{2-m}{2}}+\frac{2-m}{2} \lambda C M_{k}^{m} \pi^{\frac{m}{2}} \cdot E\left[\left(\sigma^{\max }\right)^{m}\right] t\right)^{\frac{2+m}{2-m}}-l_{o}^{\frac{2+m}{2}}\right]
$$

$C$ - material constant in Paris formula;

$M_{k}$ - coefficient of the finiteness of the element's dimensions and the position of the crack;

$l_{0}$ - initial crack length;

$\lambda$ - intensity of loading cycle appearing $\left(\lambda=\frac{1}{\Delta t}\right)$;

$\Delta t$ - duration of loading cycle.

For $m=2$

$u(l, t)=\frac{1}{\sqrt{2 \pi \bar{A}(t)}} e^{-\frac{(l-\bar{B}(t))^{2}}{2 \bar{A}(t)}}$

where:

$\bar{B}(t)=l_{0}\left(e^{\lambda \bar{C}_{2} t}-1\right)$

$\bar{A}(t)=\frac{1}{2} l_{0}^{2} \bar{C}_{2} \omega \quad\left(e^{2 \lambda \bar{C}_{2} t}-1\right)$

$\bar{C}_{2}=C_{2} E\left[\left(\sigma^{\max }\right)^{2}\right], C_{2}=C M_{k}^{2} \pi, \omega=\frac{E\left[\left(\sigma^{\max }\right)^{4}\right]}{\left(E\left[\left(\sigma^{\max }\right)^{2}\right]\right)^{2}}$

Probability of catastrophic damage will be determined according to the formula:

$Q_{2}(t)=\int_{l_{k r}}^{\infty} u(l, t) d l$

Fatigue reliability of an element will be :

$R_{2}(t)=\int_{-\infty}^{l_{d}<l_{k r}} u(l, t) d l$

where: $l_{k r}$ - critical crack length, 
$l_{d}$ - admissible crack length for the assumed hazard of element damage.

\section{Final relation for the assumed stages of crack development}

Element reliability providing for the stages of crack development will be :

$$
R(t)=R_{1}(t)+\left(1-R_{1}(t)\right) R_{2}(t)
$$

Unreliability, that is the special hazard of catastrophic failure will be:

$$
Q(t)=Q_{1}(t) \cdot Q_{2}(t)
$$

Relationship (26) and (27) can be described as:

$$
\begin{aligned}
& R(t)=R_{1}(t)-\left(1-R_{1}(t)\right) \int_{-\infty}^{l_{d} l_{l k r}} u(l, t) d l \\
& Q(t)=\left(1-R_{1}(t)\right) \int_{l_{k r}}^{\infty} u(l, t) d l
\end{aligned}
$$

It can be presented that the crack development stages create the parallel reliability structure. For the parallel structure, the damage takes place when all of its the constituent elements are damaged. Hence, it can be presented as follows:

$$
\begin{aligned}
& Q(t)=\left(1-R_{1}(t)\right) \int_{l_{k r}}^{\infty} u(l, t) d l \\
& R(t)=1-\left(1-R_{1}(t)\right) \int_{l_{k r}}^{\infty} u(l, t) d l \\
& R(t)=1-\left(1-R_{1}(t)\right)\left(1-\int_{-\infty}^{l_{k r}} u(l, t) d l\right)
\end{aligned}
$$

Hence, the relationship (26) is obtained:

$$
R(t)=R_{1}(t)+\left(1-R_{1}(t)\right) \int_{-\infty}^{l_{l k}} u(l, t) d l
$$

\section{Final notes}

In this paper, description of the probability of crack initiation as a random process is presented. In the presented model, the intensity of crack initiation is dependent on the change of the state of accumulated fatigue effects due to the appearance of successive loading cycles. 
Description of the stage comprising fatigue crack increase after the initiation includes derived in the work [4] function of crack length density that from the physical point of view is based on the Paris formula of exponent $m \neq 2$. The function of the crack length density is used for the determination of fatigue failure probability.

Finally presenting the stages of crack development as parallel reliability structure, relationships for reliability and the hazard of the catastrophic damage of a structure element were derived. The probability of crack initiation determined in this work and the presented function of fatigue crack length density can turn out very helpful in indestructibility examinations from the point of view of fatigue damages of aviation structures. An advantage of the presented method is the fact that it takes into consideration random values of stresses in the assumed cycle of structure operation.

Science work financed from the resources for academic research in the years 2006-2008 as research project.

\section{Bibliography}

1. Gercbach J. B.; Kordowski CH. B.: „Modele niezawodnościowe obiektów technicznych". WNT. Warsaw 1968.

2. Kocańda S.: Zmęczeniowe pękanie metali. WNT, Warsaw, 1985.

3. Szczepanik R., Tomaszek H., Jasztal M.: Zarys metody określania rozkładu czasu narastania pęknięcia elementu do wartości granicznej w warunkach zmęczenia $w$ procesie eksploatacji statku powietrznego. ZEM No. 3 (147), 2006, pp.81-89.

4. Szczepanik R., Tomaszek H., Jasztal M.: Zarys metody wyznaczenia ryzyka uszkodzenia i trwałości zmęczeniowej wybranych elementów konstrukcji lotniczych $w$ warunkach eksploatacji z zastosowaniem wzoru Parisa dla $m \neq 2$. Zagadnienia Eksploatacji Maszyn, Z.3 (151) Vol.42 2007, pp.99-110.

5. Tomaszek H., Żurek J., Jasztal M.: Zarys metody oceny trwałości zmęczeniowej wybranych elementów konstrukcji lotniczych $w$ warunkach eksploatacyjnego widma obciqżenia dla wzoru Parisa o wyktadniku $m \neq 2$. Zagadnienia Eksploatacji Maszyn, Z.3 (151) Vol.42 2007, pp.89-98. 


\section{MODEL RYZYKA USZKODZENIA WYBRANEGO ELEMENTU KONSTRUKCJI STATKU \\ POWIETRZNEGO Z UWZGLECDNIENIEM ETAPÓW ROZWOJU PĘKNIĘCIA ZMĘCZENIOWEGO}

\section{Wstęp}

Przyjmuje się, że proces powstawania uszkodzeń katastroficznych w aspekcie zmęczenia posiada etapy. Prosty przebieg procesu zmęczenia obejmuje trzy zasadnicze etapy:

- inicjację pęknięcia,

- wzrost pęknięcia,

- zniszczenie elementu konstrukcji.

Proces kształtowania ryzyka uszkodzenia katastroficznego (w szczególnym przypadku) rozpoczyna się inicjacją pęknięcia, co prowadzi do powstawania pęknięcia o odpowiedniej długości, dla którego już obowiązują zależności opisujące wzrost pęknięcia np. wzór Parisa.

Okres, w którym odbywa się proces inicjacji pęknięcia jest etapem poprzedzającym zasadniczy proces narastania długości pęknięcia do wartości krytycznej, dla której następuje zniszczenie elementu. Etap inicjacji pęknięcia można traktować jako pierwszy etap niszczenia elementu, po którym następuje drugi obejmujący narastanie pęknięcia do wartości krytycznej. W ten sposób można przyjąć, że powstaje niezawodnościowa struktura równoległa niszczenia elementu obejmująca inicjację pęknięcia, jego rozwoju i etap nagłego niszczenia konstrukcji.

\section{Określenie prawdopodobieństwa inicjacji pęknięcia na podstawie pojęć z niezawodności}

W probabilistycznym opisie uszkodzenia elementu podstawową rolę odgrywa intensywność uszkodzeń. W określeniu prawdopodobieństwa inicjacji pęknięcia elementu wykorzystamy to pojęcie zamieniając intensywność uszkodzeń na pojęcie intensywność inicjacji. Intensywność inicjacji pęknięcia będzie określone zależnością:

$\chi(t)=\lim _{\Delta t \rightarrow 0^{+}} \frac{P(t<T<t+\Delta t / T>t)}{\Delta t}$ 
gdzie:

$T$ - zmienna losowa określająca wartość czasu, w którym nastapiła inicjacja pęknięcia,

$t$ - czas eksploatacji badanego elementu konstrukcji,

$P(. .$.$) - prawdopodobieństwo zdarzenia warunkowego.$

Dla dwóch dowolnych zdarzeń warunkowych A i B zachodzi zależność:

$P(A / B)=\frac{P(A \cap B)}{P(B)}$

Zdarzenie $\quad\{t<T<t+\Delta t\} \cap\{t<T\} \quad$ pokrywa się ze zdarzeniem $\{t<T<t+\Delta t\}$. Wykorzystując powyższe zależności to wzór (1) możemy przedstawić $\mathrm{w}$ postaci:

$\chi(t)=\lim _{\Delta t \rightarrow 0^{+}} \frac{P(t<T<t+\Delta t)}{\Delta t P(T>t)}$

Stąd

$\chi(t)=\frac{f(t)}{R_{1}(t)}=\frac{-R_{1}^{\prime}(t)}{R_{1}(t)}$

gdzie:

$f(t)$ - funkcja gęstości czasu inicjacji pęknięcia,

$R_{1}(t)$ - prawdopodobieństwo, że w przedziale czasu $(0, t)$ inicjacji pęknięcia nie będzie.

Zależność (3) można zapisać w postaci następującego równania różniczkowego:

$R_{1}^{\prime}(t)+\chi(t) R_{1}(t)=0$

Równanie (4) dla warunku początkowego $R(t=0)=1$ ma następujące rozwiązanie:

$R_{1}(t)=e^{-\int_{0}^{t} \chi(t) d t}$

Zależność (5) określa prawdopodobieństwo tego, że w przedziale $(0, t)$ inicjacji pęknięcia nie będzie. Stąd prawdopodobieństwo inicjacji pęknięcia w przedziale czasu $(0, t)$ będzie określone zależnością:

$Q_{1}(t)=1-R_{1}(t)$

Gdy $\chi(t)=\chi=$ const to zależność (5) i (6) przyjmują postać:

$R_{1}(t)=e^{-\chi \cdot t}$

$Q_{1}(t)=1-e^{-\chi \cdot t}$ 
Oszacowanie intensywności inicjacji pęknięcia $\chi$ można dokonać wykorzystując zależność powstałą z zastosowania zasady momentów:

$$
\chi=\frac{w}{\sum_{k=1}^{w} t_{k}}
$$

gdzie: $w$ - liczba obserwowanych elementów w czasie eksploatacji statku powietrznego,

$t_{k}$ - jest czasem do chwili inicjacji pęknięcia w $k$-tym układzie liczonym od początku eksploatacji.

\section{Określenie prawdopodobieństwa inicjacji pęknięcia jako procesu losowego}

Przyjmujemy, że inicjacja pęknięcia w elemencie następuje w wyniku kumulacji degradacji struktury wewnętrznej elementu na skutek działania zmiennego obciążenia. W wyniku działania obciążenia zmiennego następuje spiętrzenie objawów zmęczenia $\mathrm{w}$ różnych miejscach elementu np. na różnego rodzaju ,przeszkodach”.

Zakładamy, że wśród miejsc spiętrzania skutków działania jest jedno wiodące i w nim następuje inicjacja jako wynik kumulacji skutków zmęczenia. Dla przykładu można podać, że na tej wybranej „przeszkodzie”, w jej otoczeniu następuje między innymi spiętrzanie dyslokacji.

Niech $\Psi$ będzie parametrem, który służy do pomiaru skumulowanych destrukcyjnych objawów zmęczenia struktury elementu w otoczeniu przeszkody. Można więc przyjąć, że parametrem prognostycznym do oceny szansy powstania pęknięcia (jego inicjacji) jest parametr $\Psi$. Dokonujemy dyskretyzacji parametru prognostycznego $\Psi$ w następujący sposób: $E_{0}, E_{1}, E_{2}, \ldots, E_{k}, \ldots$ punkty te nazywamy stanami procesu narastania skutków zmęczenia przed inicjacją pęknięcia w wyniku działania obciążenia. Skumulowane objawy zmęczenia w otoczeniu przeszkody sprzyjają inicjacji pęknięcia.

Przyjmujemy, że z każdego stanu istnieje określone prawdopodobieństwo pojawienia się pęknięcia (inicjacja pęknięcia). Wraz ze wzrostem stanu $E_{i}(i=0,1,2, \ldots)$ następuje wzrost prawdopodobieństwa inicjacji pęknięcia. 


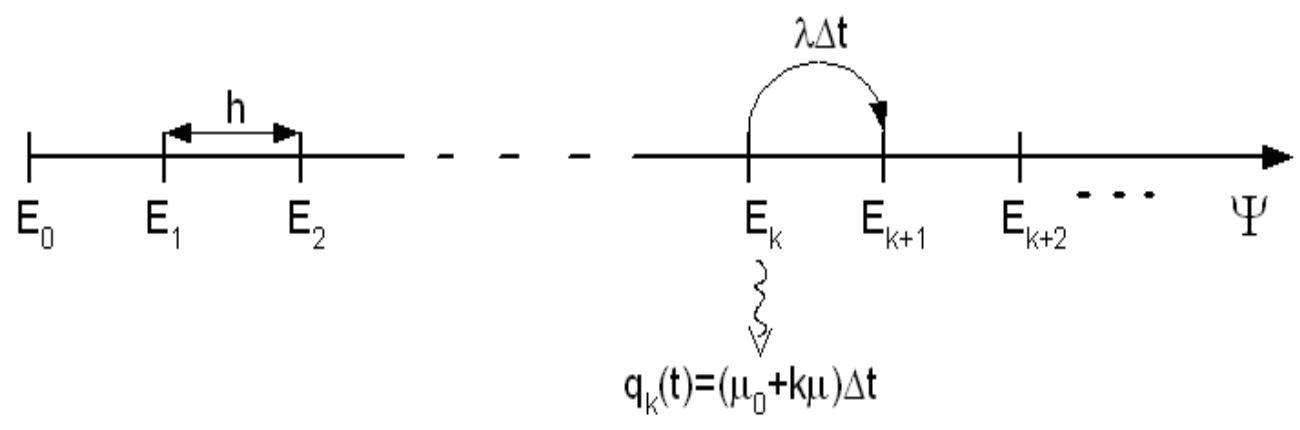

Rys.1. Schemat dyskretyzacji parametru diagnostycznego

Rysunek 1 przedstawia narastanie objawów zmęczenia $\mathrm{w}$ otoczeniu przeszkody pod wpływem obciążenia, co wiąże się z osiągnięciem coraz to wyższego stanu. Czynnikiem wymuszającym zmianę stanu jest prawdopodobieństwo pojawienia się cyklu obciążenia $\lambda \Delta t$, gdzie $\lambda$ jest intensywnością pojawienia się cyklu obciążenia elementu. W każdym stanie istnieje prawdopodobieństwo inicjacji pęknięcia.

$q_{k}(t)=\left(\mu_{0}+k \mu\right) \Delta t$

gdzie:

$\mu_{0}$ - intensywność inicjacji pęknięcia w chwili początkowej,

$k \mu$ - intensywność inicjacji pęknięcia zależna od stanu skumulowanych skutków zmęczenia,

$h$ - średnia wartość przyrostu parametru diagnostycznego w czasie $\Delta t$, $\lambda \Delta t$ - prawdopodobieństwo pojawienia się cyklu obciążenia elementu $\mathrm{W}$ czasie $\Delta t$.

Niech $P_{k}(t)$ oznacza prawdopodobieństwo, że $\mathrm{w}$ chwili $t$ wartość parametru diagnostycznego osiąnęła stan $E_{k}$ (gdzie $k=0,1,2, \ldots$ ). Można dla tych ustaleń ułożyć następujący układ równań (o nieskończonej ilości równań) [1]:

$P_{0}(t+\Delta t)=P_{0}(t)\left[1-\left(\mu_{0}+\lambda\right) \Delta t\right]+0(\Delta t)$

$$
\begin{aligned}
& \vdots \\
& P_{k}(t+\Delta t)=P_{k}(t)\left[1-\left(\mu_{0}+k \mu+\lambda\right) \Delta t\right]+P_{k-1}(t) \lambda \Delta t+0(\Delta t)
\end{aligned} \quad d l a k=1,2, \ldots
$$

Po przekształceniu i podzieleniu obu stron $k$-tego równania przez $\Delta t \mathrm{z}$ przejściem do granicy z $\Delta t \rightarrow 0$ otrzymujemy następujący układ równań: 


$$
P_{0}^{\prime}(t)=-\left(\mu_{0}+\lambda\right) P_{0}(t)
$$

$$
\text { dla } k=1,2, \ldots
$$

$P_{k}^{\prime}(t)=-\left(\mu_{0}+\lambda+k \mu\right) P_{k}(t)+\lambda P_{k}(t)$

Warunek początkowy dla każdego $\mathrm{z}$ tych równań możemy zapisać $\mathrm{W}$ następującej postaci:

$P_{i}(0)=\left\{\begin{array}{l}1 \text { dla } i=0 \\ 0 \text { dla } i \neq 0\end{array}\right.$

Rozwiązanie dla $k=0$ :

$P_{0}(t)=-C_{0} e^{-\left(\mu_{0}+\lambda\right) t}$

Rozwiązanie dla dowolnego $k$ :

$P_{k}(t)=\frac{1}{k !}\left(\frac{\lambda}{\mu}-\frac{\lambda}{\mu} e^{-\mu t}\right)^{k} e^{-\left(\mu_{0}+\lambda\right) t}$

dla $k=1,2,3 \ldots$

wykorzystując zależności (14) i (15) można określić niezawodność elementu:

$$
\begin{aligned}
& R(t)=\sum_{k=0}^{\infty} P_{k}(t) \\
& R(t)=\sum_{k=0}^{\infty} \frac{1}{k !}\left(\frac{\lambda}{\mu}-\frac{\lambda}{\mu} e^{-\mu t}\right)^{k} e^{-\left(\mu_{0}+\lambda\right) t}
\end{aligned}
$$

Należy zauważyć, że zachodzi równość:

$$
\sum_{k=0}^{\infty} \frac{1}{k !}\left(\frac{\lambda}{\mu}-\frac{\lambda}{\mu} e^{-\mu t}\right)^{k}=e^{\frac{\lambda}{\mu}-\frac{\lambda}{\mu} e^{-\mu t}}
$$

Stąd:

$$
R(t)=e^{\frac{\lambda}{\mu}\left(1-e^{-\mu t}\right)-\left(\mu_{0}+\lambda\right) t}
$$

Prawdopodobieństwo, że do chwili $t$ nie nastąpi inicjacja pęknięcia, można określić zależnością:

$R_{1}(t)=\sum_{k=0}^{\infty} P_{k}(t)$

Prawdopodobieństwo, że do chwili $t$ nastąpi inicjacja pęknięcia, można określić zależnością:

$Q_{1}(t)=P\{T \leq t\}=1-R_{1}(t)=F(t)$ 
Po wykonaniu operacji sumowania otrzymujemy następującą postać rozwiązania:

$Q(t)=F(t)=1-e^{\frac{\lambda}{\mu}-\left(\lambda+\mu_{0}\right) t-\frac{\lambda}{\mu} e^{-\mu t}}$

Zależność (21) określa prawdopodobieństwo inicjacji pęknięcia w przedziale czasu $(0, t)$.

\section{Zależność na określenie narastania pęknięcia po inicjacji}

W pracy [4] funkcja gęstości długości pęknięcia określona została w postaci dla $m \neq 2$.

$u(l, t)=\frac{1}{\sqrt{2 \pi A(t)}} e^{-\frac{(l-B(t))^{2}}{2 A(t)}}$

gdzie:

$l$-długość pęknięcia,

$t$ - nalot statku powietrznego,

$B(t)$ - wartość oczekiwana długości pęknięcia dla $m \neq 2$ określona wzorem:

$$
B(t)=\left[l_{o}^{\frac{2-m}{2}}+\frac{2-m}{2} \lambda C M_{k}^{m} \pi^{\frac{m}{2}} E\left[\left(\sigma^{\max }\right)^{m}\right] t\right]^{\frac{2}{2-m}}-l_{o}
$$

$A(t)$ - wariancja długości pęknięcia dla $m \neq 2$ określona wzorem:

$$
\begin{aligned}
A(t)= & \frac{2}{2+m} C M_{k}^{m} \pi^{\frac{m}{2}} \frac{E\left[\left(\sigma^{\max }\right)^{2 m}\right]}{E\left[\left(\sigma^{\max }\right)^{m}\right]} . \\
& \cdot\left[\left(l_{o}^{\frac{2-m}{2}}+\frac{2-m}{2} \lambda C M_{k}^{m} \pi^{\frac{m}{2}} \cdot E\left[\left(\sigma^{\max }\right)^{m}\right] t\right)^{\frac{2+m}{2-m}}-l_{o}^{\frac{2+m}{2}}\right]
\end{aligned}
$$

$C$ - stała materiałowa we wzorze Parisa;

$M_{k}$ - współczynnik skończoności wymiarów elementu i miejsca położenia pęknięcia;

$l_{0}$ - początkowa długość pęknięcia;

$\lambda$ - intensywność pojawiania się cykli obciążenia $\left(\lambda=\frac{1}{\Delta t}\right)$;

$\Delta t$ - czas trwania cyklu obciążenia.

Dla $m=2$

$u(l, t)=\frac{1}{\sqrt{2 \pi \bar{A}(t)}} e^{-\frac{(l-\bar{B}(t))^{2}}{2 \bar{A}(t)}}$ 
gdzie:

$$
\begin{aligned}
& \bar{B}(t)=l_{0}\left(e^{\lambda \bar{C}_{2} t}-1\right) \\
& \bar{A}(t)=\frac{1}{2} l_{0}^{2} \bar{C}_{2} \omega \quad\left(e^{2 \lambda \bar{C}_{2} t}-1\right) \\
& \bar{C}_{2}=C_{2} E\left[\left(\sigma^{\max }\right)^{2}\right], C_{2}=C M_{k}^{2} \pi, \omega=\frac{E\left[\left(\sigma^{\max }\right)^{4}\right]}{\left(E\left[\left(\sigma^{\max }\right)^{2}\right]\right)^{2}}
\end{aligned}
$$

Prawdopodobieństwo uszkodzenia katastroficznego określone będzie wzorem:

$$
Q_{2}(t)=\int_{l_{l r}}^{\infty} u(l, t) d l
$$

Niezawodność zmęczeniowa elementu będzie:

$$
R_{2}(t)=\int_{-\infty}^{l_{d}<l_{k r}} u(l, t) d l
$$

gdzie: $l_{k r}$ - krytyczna długość pęknięcia,

$l_{d}$ - dopuszczalna długość pęknięcia dla przyjętego ryzyka uszkodzenia elementu.

\section{Zależność końcowa dla przyjętych etapów rozwoju pęknięcia}

Niezawodność elementu z uwzględnieniem etapów rozwoju pęknięcia będzie:

$$
R(t)=R_{1}(t)+\left(1-R_{1}(t)\right) R_{2}(t)
$$

Zawodność, czyli określone ryzyko uszkodzenia katastroficznego będzie $Q(t)=Q_{1}(t) \cdot Q_{2}(t)$

Zależność (26) i (27) można napisać w postaci:

$$
\begin{aligned}
& R(t)=R_{1}(t)-\left(1-R_{1}(t)\right) \int_{-\infty}^{l_{d}<l_{k r}} u(l, t) d l \\
& Q(t)=\left(1-R_{1}(t)\right) \int_{l_{k r}}^{\infty} u(l, t) d l
\end{aligned}
$$

Można przedstawić, że etapy rozwoju pęknięcia tworzą równoległą strukturę niezawodnościową. Dla struktury równoległej uszkodzenie jej następuje, gdy wszystkie elementy ją tworzące uszkodzą się. Stąd można napisać, że: 


$$
\begin{aligned}
& Q(t)=\left(1-R_{1}(t)\right) \int_{l_{k r}}^{\infty} u(l, t) d l \\
& R(t)=1-\left(1-R_{1}(t)\right) \int_{l_{k r}}^{\infty} u(l, t) d l \\
& R(t)=1-\left(1-R_{1}(t)\right)\left(1-\int_{-\infty}^{l_{k r}} u(l, t) d l\right)
\end{aligned}
$$

Stąd otrzymujemy zależność (26)

$$
R(t)=R_{1}(t)+\left(1-R_{1}(t)\right) \int_{-\infty}^{l_{k r}} u(l, t) d l
$$

\section{Uwagi końcowe}

W niniejszym artykule przedstawiono opis prawdopodobieństwa inicjacji pęknięcia jako procesu losowego. W prezentowanym modelu intensywność inicjacji pęknięcia zależna jest od zmiany stanu skumulowanych skutków zmęczenia na skutek pojawiania się kolejnych cykli obciążenia.

Opis etapu narastania pęknięcia zmęczeniowego po inicjacji zawiera wyprowadzoną w pracy [4] funkcję gęstości długości pęknięcia, która od strony fizycznej bazuje na zależności Parisa o wykładniku $m \neq 2$. Funkcja gęstości długości pęknięcia służy do określenia prawdopodobieństwa uszkodzenia zmęczeniowego.

Ostatecznie przedstawiając etapy rozwoju pęknięcia jako równoległą strukturę niezawodnościową wyprowadzono zależności na niezawodność oraz ryzyko uszkodzenia katastroficznego elementu konstrukcji. Wyznaczone $\mathrm{w}$ niniejszej pracy prawdopodobieństwo inicjacji pęknięcia oraz przedstawiona funkcja gęstości długości pęknięcia zmęczeniowego, mogą okazać się bardzo pomocne w badaniach trwałościowych w aspekcie uszkodzeń zmęczeniowych konstrukcji lotniczych. Zaletą prezentowanej metody jest fakt, że uwzględnia ona losowe wartości naprężeń w przyjętym cyklu eksploatacyjnym konstrukcji.

Praca naukowa finansowana ze środków na naukę w latach 2006-2008 jako projekt badawczy. 


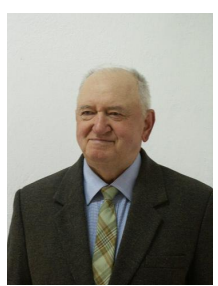

Prof. dr hab. inż. Henryk Tomaszek, absolwent Wojskowej Akademii Technicznej i Uniwersytetu Warszawskiego. Wieloletni pracownik naukowo-dydaktyczny Wojskowej Akademii Technicznej, oraz pracownik naukowy Instytutu Technicznego Wojsk Lotniczych. Główne kierunki działalności naukowej to: mechanika, uzbrojenie lotnicze oraz niezawodność i eksploatacja systemów technicznych.

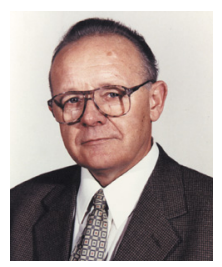

P Dr. Józef Żurek, professor at Air Force Institute of Technology in Warsaw. Specialisation: budowa i eksploatacja maszyn, transport, bezpieczeństwo i niezawodność systemów,

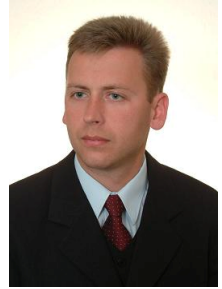

Major Michal Jasztal Polish Air Force studied at Military Univeristy of Technology since 1994 to 1999. M. Sc. in Electromechanics specialized in Aircraft's Armament. In 2003 achieved Ph.D. in Mechanical Engineering specialized in airframe structural strength. Since 1999 senior lecturer in Military Univeristy of Technology Faculty of Armament and Aviation Engineering. 